\title{
Cerebral Vasospasm in a Double-Injection Model in Rabbit
}

\author{
Aldo Spallone, M.D., and Francesco Saverio Pastore, M.D. \\ Division of Neurosurgery, Second University of Rome, "Tor Vergata," Rome, Italy
}

Spallone A, Pastore FS. Cerebral vasospasm in a double-injection model in rabbit. Surg Neurol 1989;32:408-17.

The present study was designed to assess the occurrence of cerebral vasospasm following an experimental subarachnoid hemorrhage model in rabbits. Sixty-nine New Zealand albino rabbits were used in this study. One milliliter of fresh arterial blood was injected through the surgically exposed atlanto-occipital membrane over a period of 20 seconds. The procedure was then repeated 24 hours later. Fifty animals underwent digital subtraction angiography at one of the following prefixed intervals: 1 , 3 , or 8 days after the second injection hemorrhage. Nineteen animals underwent one angiographic examination prior to the instillation of the intracisternal blood. This procedure was followed by a repeated angiography 3 days after the second experimental subarachnoid hemorrhage. For the purpose of evaluation, the films were magnified 10-fold and the diameter of the basilar artery as well as that of the extracranial vertebral artery at three different levels were measured. We assessed the diameter of the basilar artery as well as the mean ratio extracranial vertebral artery/basilar artery diameters. This ratio was considered to minimize anatomical and technical variabilities. The results in the first 50 animals showed a trend suggesting that spasmogenic activity reaches a peak at about the third day after subarachnoid hemorrhage. These results were confirmed in the latter 19 animals. However, mortality in this group was high: $50 \%$. This double-injection model of subarachnoid hemorrhage in rabbits consistently reproduced cerebral vascular spasm 3 days after repeated subarachnoid hemorrhage. However, its usefulness as an experimental model for subarachnoid hemorrhage is limited practically by the high animal mortality in the protocols where repeated angiographic studies are necessary.

KEY WORDS: Experimental subarachnoid hemorrhage; Cerebral spasm; Angiographic study; Rabbit

Address reprint requests to: Aldo Spallone, M.D., Cattedra di Neurochirurgia, Seconda Università degli Studi di Roma, "Tor Vergata," Via Orazio Raimondo, 8, I-00173 Rome, Italy.

Received January 11, 1988; accepted April 14, 1989.

\section{Introduction}

Ischemic complications, presumably related to cerebral vasospasm following subarachnoid hemorrhage ( $\mathrm{SAH}$ ), are a major source of disappointing results seen in the management of ruptured intracranial aneurysms [11]. Extensive research in cerebral vasospasm following $\mathrm{SAH}$ is necessary in the hope of improving the results of surgical intervention. Several animal models of $\mathrm{SAH}$ have been reported in the literature. The aim of the present study was to assess the validity of a new model of $\mathrm{SAH}$ in rabbit, an animal seldom used in $\mathrm{SAH}$ experiments $[5,8,15,19]$.

\section{Material and Methods}

Fifty-nine white New Zealand rabbits, weighing approximately $2 \mathrm{~kg}$ were used in this study. For the experimental procedure, the animals were premedicated with $\mathrm{N}-3$ propionilphenothiazine (Combelen, Bayer), $0.5 \mathrm{~mL} / \mathrm{kg}$ via intramuscular injection, and were then anesthetized with Nembutal, $20 \mathrm{mg} / \mathrm{kg}$ intravenously. Body temperature was maintained constant at $37^{\circ}$ by a heating pad. The auricular artery (or the femoral artery in cases of an unsuccessful canulation) was catheterized for blood pressure monitoring and arterial blood sampling. With the head held in a stereotaxic frame, the atlanto-occipital membrane was exposed surgically by careful dissection of the nuchal muscles. Then $1 \mathrm{~mL}$ of fresh arterial blood was injected over a period of 20 seconds into the cisterna magna via a No. 27-gauge needle. Immediately thereafter, the animals were placed head down for 5 minutes to facilitate the intracranial dispersion of blood. The duration of postinjection apnea was monitored.

The animals who developed respiratory difficulties after the injection were ventilated mechanically via a well-fitted mask connected to a Harvard ventilator (550830-large rodent ventilator) flowing at $30 \mathrm{~mL} / \mathrm{kg}$ and 14 breaths per minute. Blood pressure was continuously monitored during the experiment, and arterial blood gases were checked before and after the subarachnoid injection of blood. Appropriate antibiotics were administered intramuscularly at the end of the procedure. Twenty-four hours later, the entire proce- 


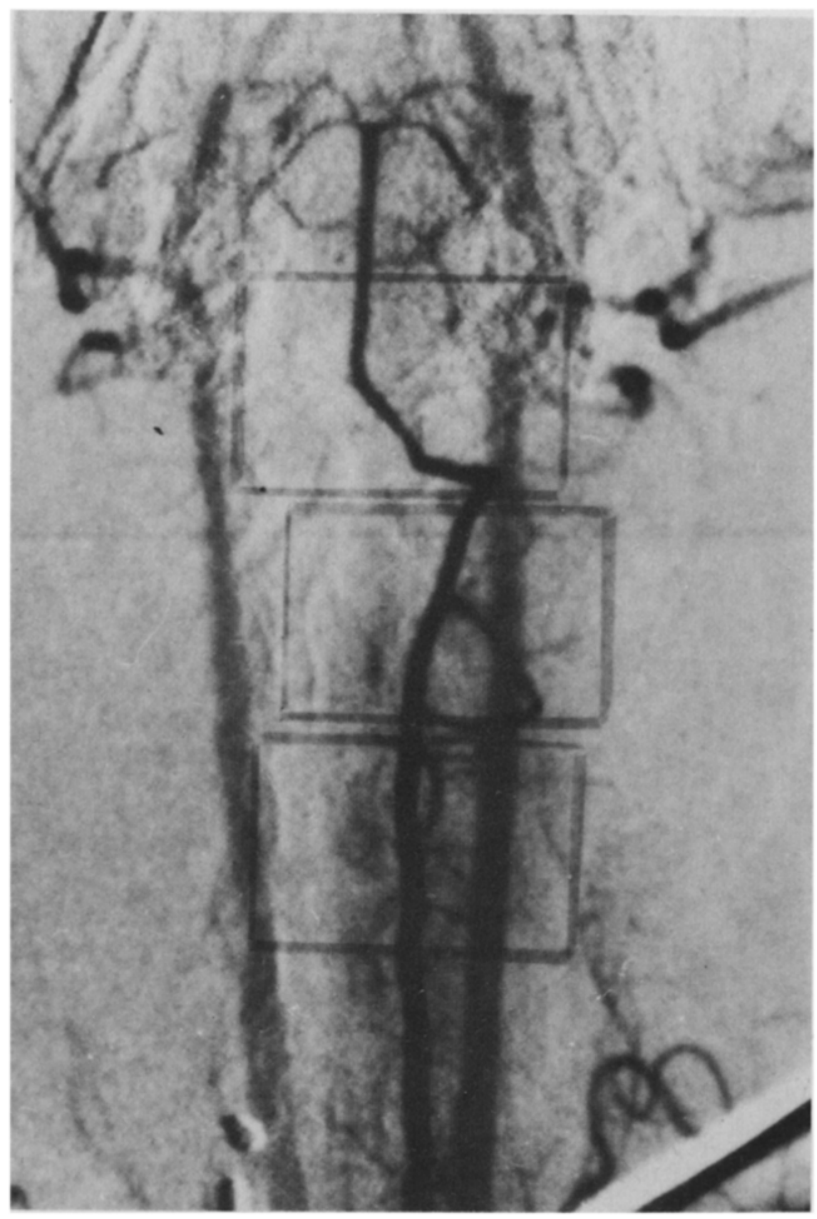

A

Figure 1. (A) Angiography in a control animal. (B) Magnified view of the intracranial vertebral and basilar artery (reproduced $\times 10$ ). (C) Magnified view of the extracranial tertebral artery (reproduced $\times 10$ ).

dure was repeated. Following this, the animals were monitored clinically at least twice daily.

The time of the second hemorrhage was considered day zero (day 0). The first 50 animals (group A) underwent angiographic examination at one of the following prefixed intervals: day 1 , day 3 , or day 8 . Some day 1 and day 3 animals also underwent computed tomography (CT) scanning examination. In three animals, saline instead of blood was injected into the cisterna magna. In this group, angiography was performed 3 days after the second and last injection.

In the last 19 animals (group B), a control angiogram was obtained just prior to the first intracisternal injection of blood. A final angiogram was then performed 3 days after the second experimental SAH.

For the purpose of angiography, the animals were

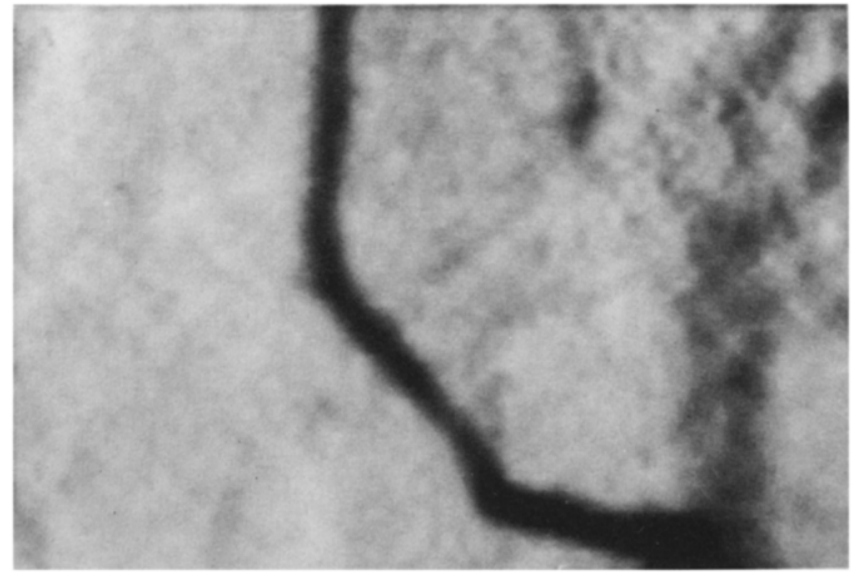

B

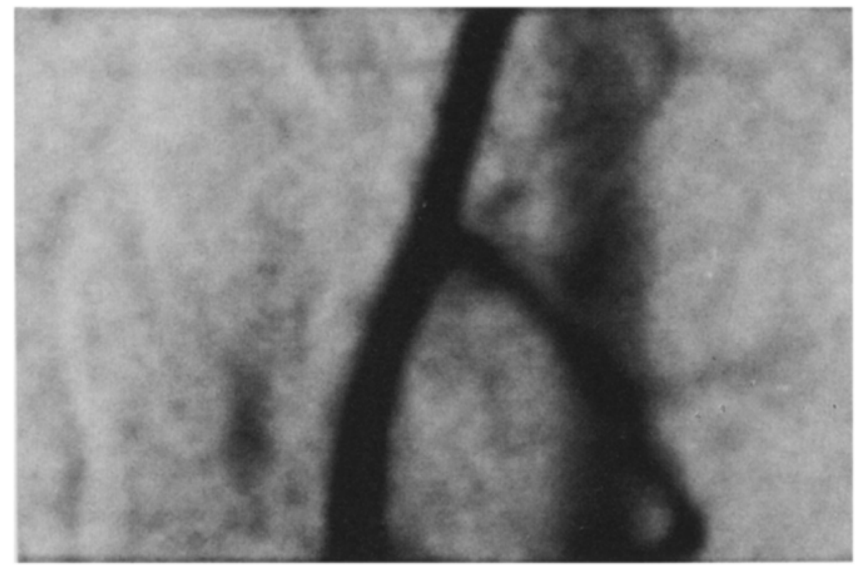

C

again anesthetized as previously, and the femoral artery was catheterized with a No. 4.0 French (Flexo Pulmocath Selon orandjean) catheter. Positioning of the tip of the catheter into the left subclavian artery close to the origin of the vertebral artery was checked with fluoroscopy. Digital angiography (Angiotron-Siemens Electronics) was performed using standardized conditions (i.e., distance between the head of the animal and the source of radiation, angiographic mask) via manual injection of $5 \mathrm{~mL}$ of water-soluble contrast agent (Conray 60 ). In the group $B$ animals, the catheter was removed following the control angiographic study and a temporary clip was placed on the artery proximal to the puncture site, the latter in order to allow a later, second catheterization. The animals were sacrificed following the final angiogram, and their brains were removed for gross inspection.

The diameter of the basilar artery was measured at the junction between its lower and middle third, using a 10 -fold magnification of the subtraction films. Appropriate calipers were used for at least two different 


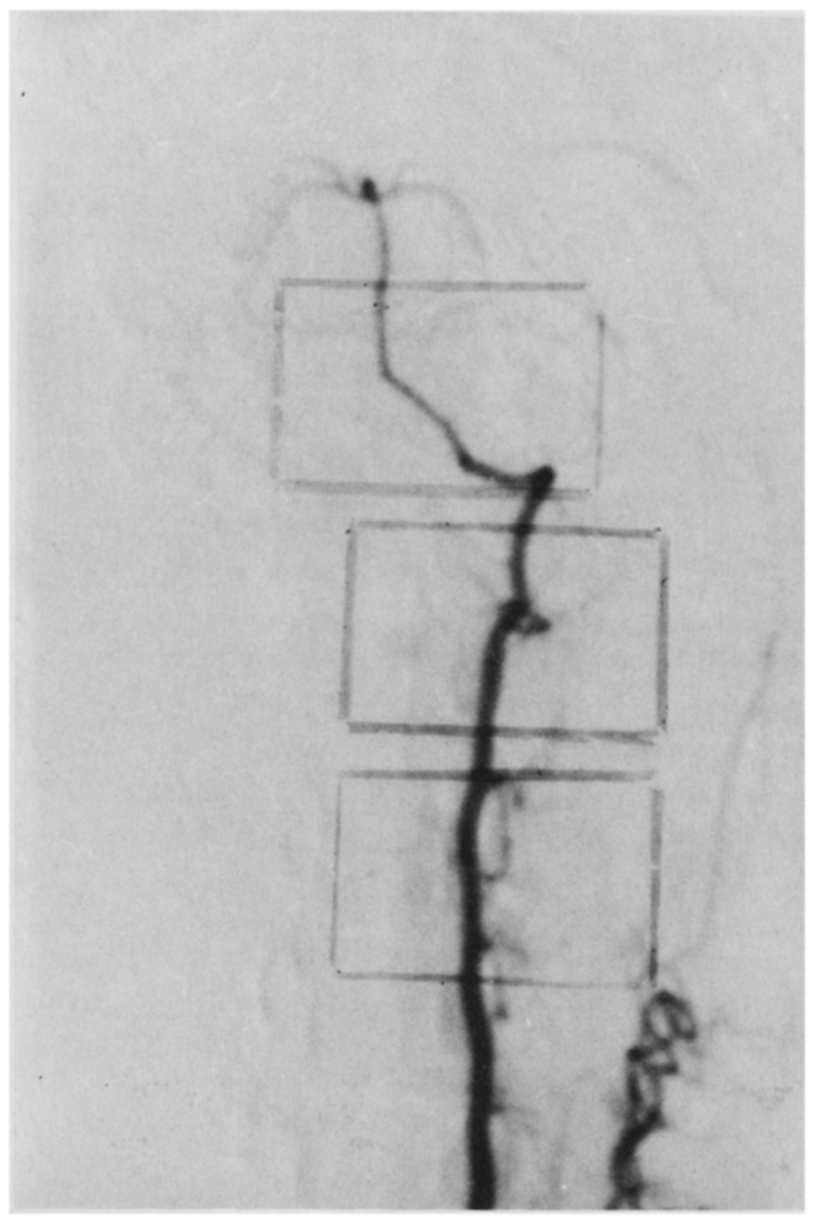

$\mathbf{A}$

evaluations. We also considered the ratio between the mean diameter of the extracranial vertebral artery (measured at two different levels) and that of the basilar artery, the latter to minimize the possible influence of changes in the distance between the animal and the $\mathbf{x}$-ray source, plus anatomical variability.

Statistical analysis of the data was performed using the Student's t-test and Fisher's analysis of variance.

\section{Results}

\section{Group A (50 Animals)}

General observations. We recorded 10 deaths (20\%) in this group, including 2 deaths that it is likely were related to the angiographic procedure. The incidence of drowsiness was high, being present in 24 rabbits. Hemiparesis was noted in two cases. Apnea after SAH was observed in $50 \%$ of animals but in none of the salineinjected rabbits, with intervals between 8 and $30 \mathrm{sec}$ onds. As a rule, the animals presenting with apnea did

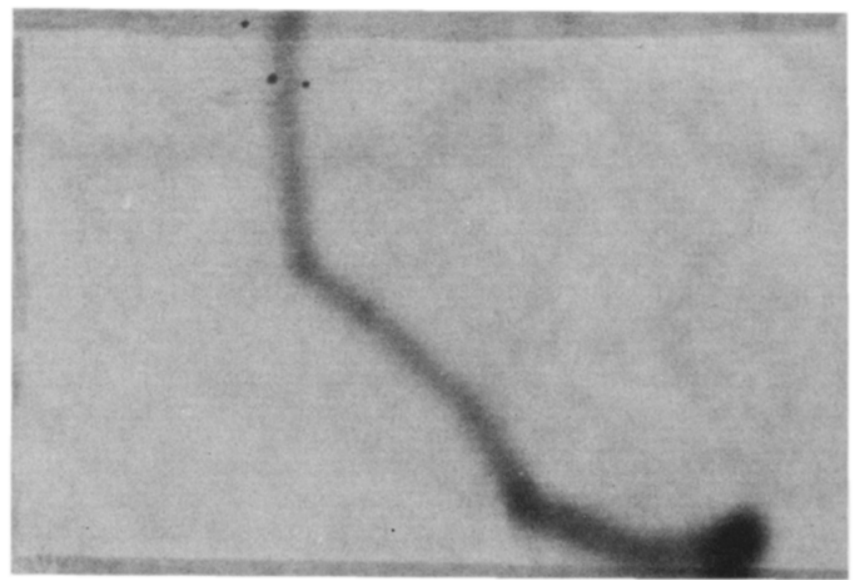

B

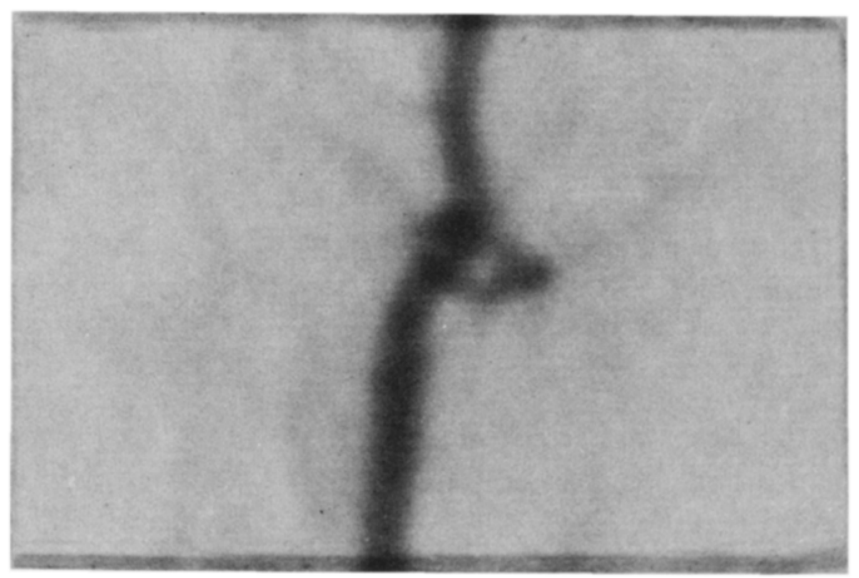

C

Figure 2. (A) Angiography in an animal 1 day after $S A H$. (B) Magnified view of the intracranial vertebral and basilar artery (reproduced $\times 10$ ). (C) Magnified view of the extracranial vertebral artery (reproduced $\times 10)$.

not show a substantially different clinical course in comparison with nonapneic animals. Mechanical ventilation was required in four cases where apnea exceeded a duration of 30 seconds. Nevertheless, two of these animals did not recover from acute respiratory distress occurring after the subarachnoidal injection of blood in spite of adequate ventilation and resuscitative maneuvers. In these two animals, arterial blood gas monitoring showed values compatible with the clinical syndrome of irreversible acute respiratory insufficiency $\left(\mathrm{PO}_{2}<60\right.$ $\mathrm{mm} \mathrm{Hg}, \mathrm{PCO}_{2}>40 \mathrm{~mm} \mathrm{Hg}, \mathrm{pH}$ about 7.25$)$.

Blood pressure monitoring consistently showed a rise in the mean values immediately after the experimental hemorrhage, and this subsided in about 10 seconds. 


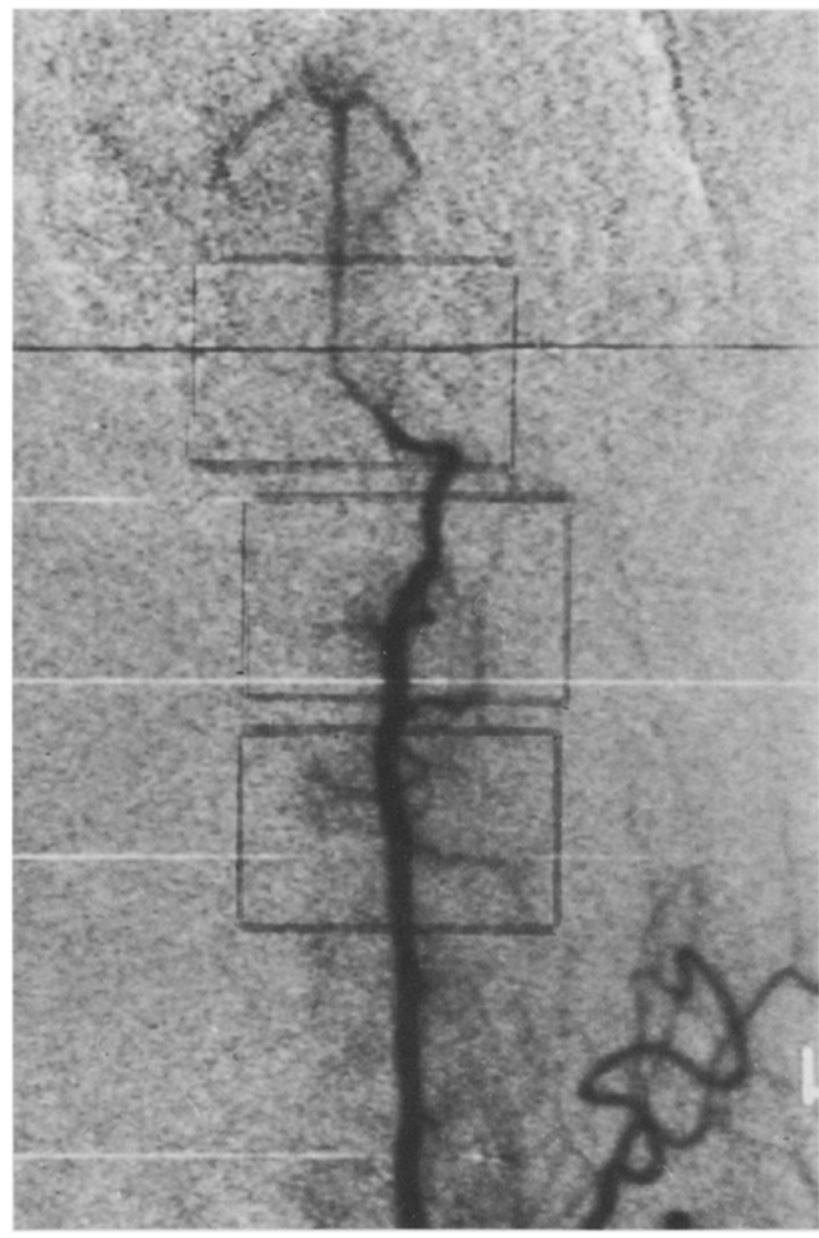

A

Figure 3. (A) Angiography in a rabbit 3 days following SAH. (B) Magnified view of the intracranial vertebral and basilar artery (reproduced $\times 10$ ). (C) Magnified view of extracranial vertebral artery (reproduced $\times 10)$.

Arteriograpbic results. The subtraction films of the vertebrobasilar system were of satisfactory quality in 38 of the 40 cases (Figures 1-5). The numerical data obtained from the experimental animals are summarized in Table 1.

Values obtained from the "saline" group were similar to the mean values of control group. Figure 6 is a graphic representation of the observed angiographic values. As expected, there was an inverse relationship between the measured diameters of the basilar arteries and the ratio mean extracranial vertebral artery/basilar artery $(\mathrm{MV} / \mathrm{BA})$. The increase in the ratio suggested a decreasing diameter of the basilar without substantial changes in that of extracranial vertebral artery. There was a trend showing a reduction in the diameter of the

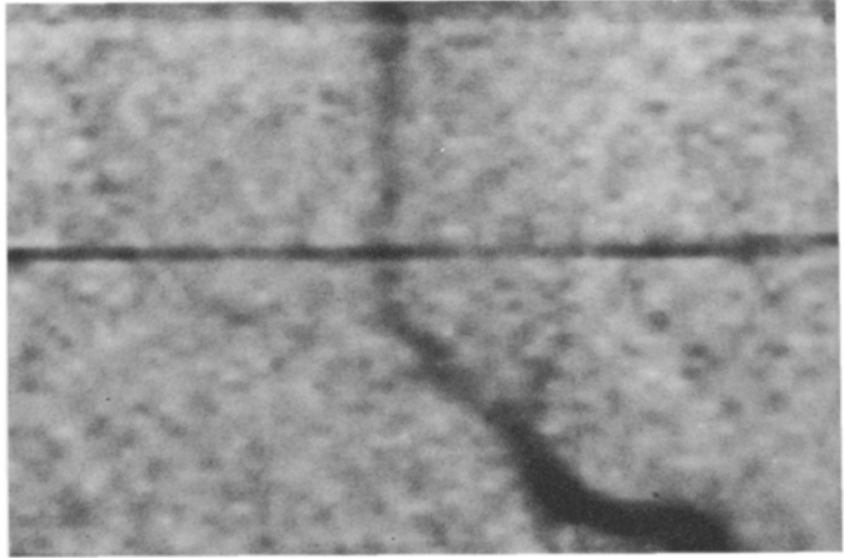

B

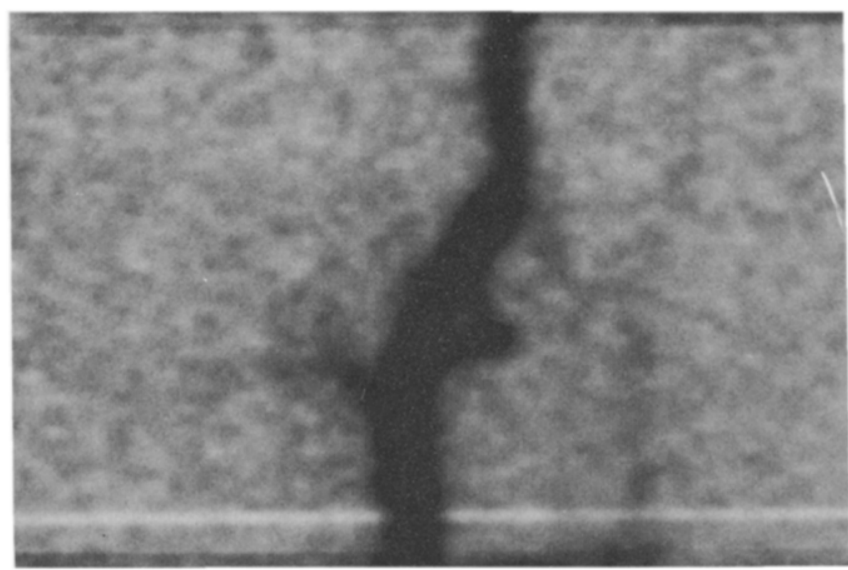

C

basilar artery in SAH animals, with a peak on day 3 after the last hemorrhage. This trend appears to be more evident when the ratio $\mathrm{MV} / \mathrm{BA}$ was used for the measurements.

Statistical comparison of the changes in the diameters of the basilar arteries showed significant difference between controls and day 1 animals $(p<0.05)$ and between controls and day 3 animals $(p<0.005)$. A statistically significant difference existed between day 1 animals and day 3 animals $(p<0.05)$.

No difference was detected between control animals, day 8 animals, and the saline-injected animals.

On the other hand, statistical comparison of the MV/BA ratio values between controls and day 3 rabbits showed a highly significant difference $(p<0.001)$. The same $p$ value $(<0.001)$ was obtained comparing MV/BA ratios of day 1 and day 3 animals.

No significant difference was found in control group $\mathrm{MV} / \mathrm{BA}$ values when compared respectively to either those of day 8 group or day 1 group. 


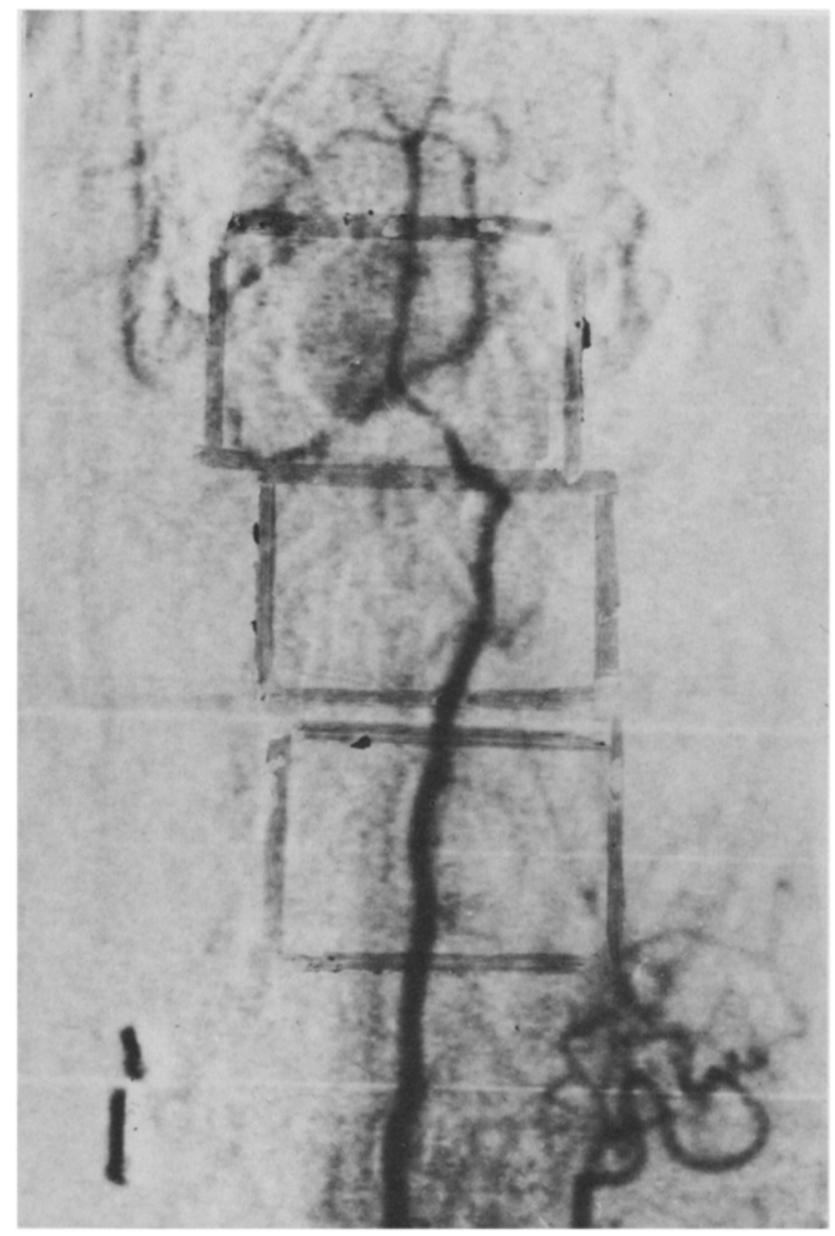

A

Gross patbological findings. Autopsy findings demonstrated the presence of blood clots on the basal surface of the brain in the day 1 animal group (Figure 7). This finding was in agreement with the CT scan results (Figure 8). No clots were found in the day 3 group specimens.

\section{Group B (19 Animals)}

General observations. Mortality related to the procedure was very high. In fact, 19 animals were required to obtain 10 complete angiographic studies. In particular, five animals died during the second angiography, three after the second hemorrhage, and one between the first and second hemorrhage. In those animals, monitoring of vital signs showed hypotension and respiratory failure as a cause of death. Four of the survivors showed a milder form of the same syndrome during the second angiography, but these animals recovered.

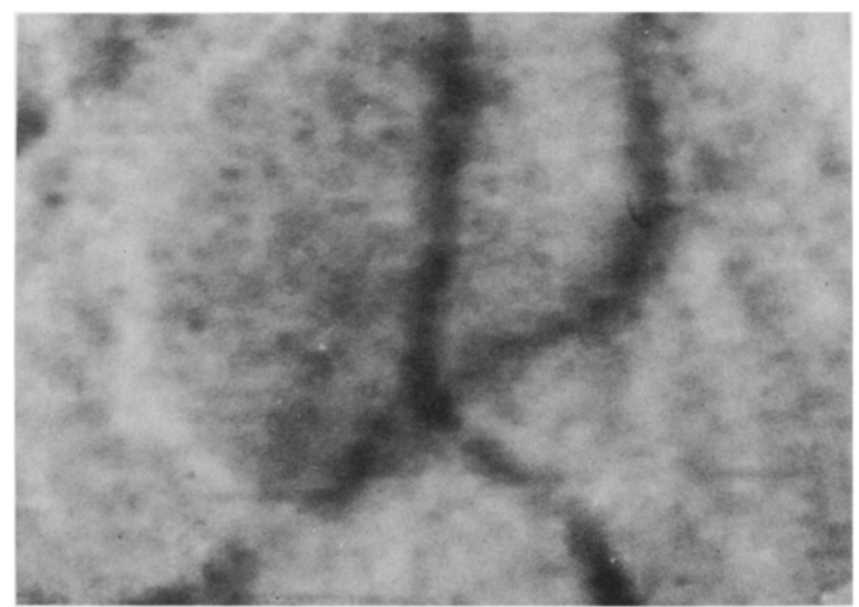

B

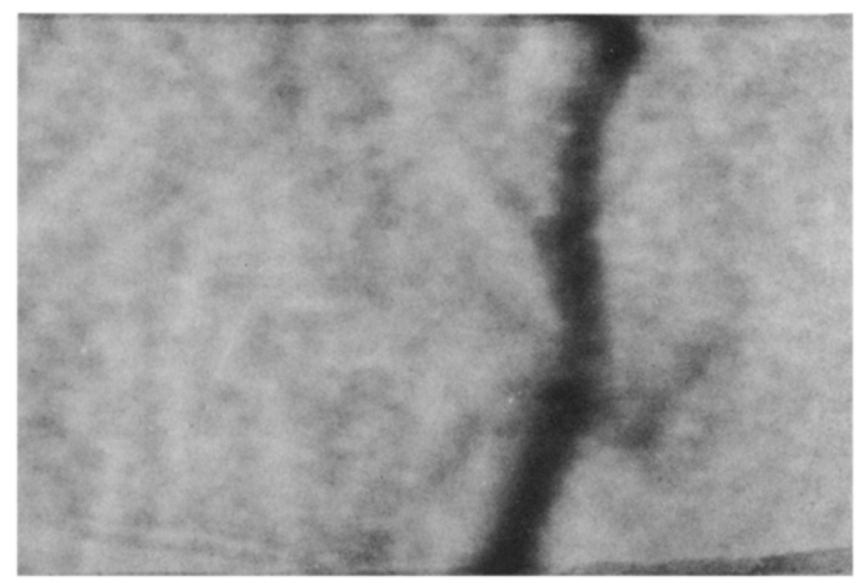

C

Figure 4. (A) Angiography in an animal 8 days following SAH. (B) $M a g n i f i e d$ view of the intracranial vertebral and basilar artery (reproduced $\times 10)$. (C) Magnified view of the exiracranial vertebral artery (reproduced $\times 10)$.

Arteriograpbic results. We found the same pattern with a vessel caliber reduction of $15 \%-20 \%$ for the basilar artery 3 days after the SAH (Figures 9-12). The data are summarized in Table 2 . Statistical analysis using the Student's t-test again showed statistical significance $(p<0.05)$.

Gross pathological findings. As expected, no clots were found macroscopically in this group of animals.

\section{Discussion}

The occurrence of ischemic complications presumably owing to vasospasm following $\mathrm{SAH}$ is a grave prognos- 


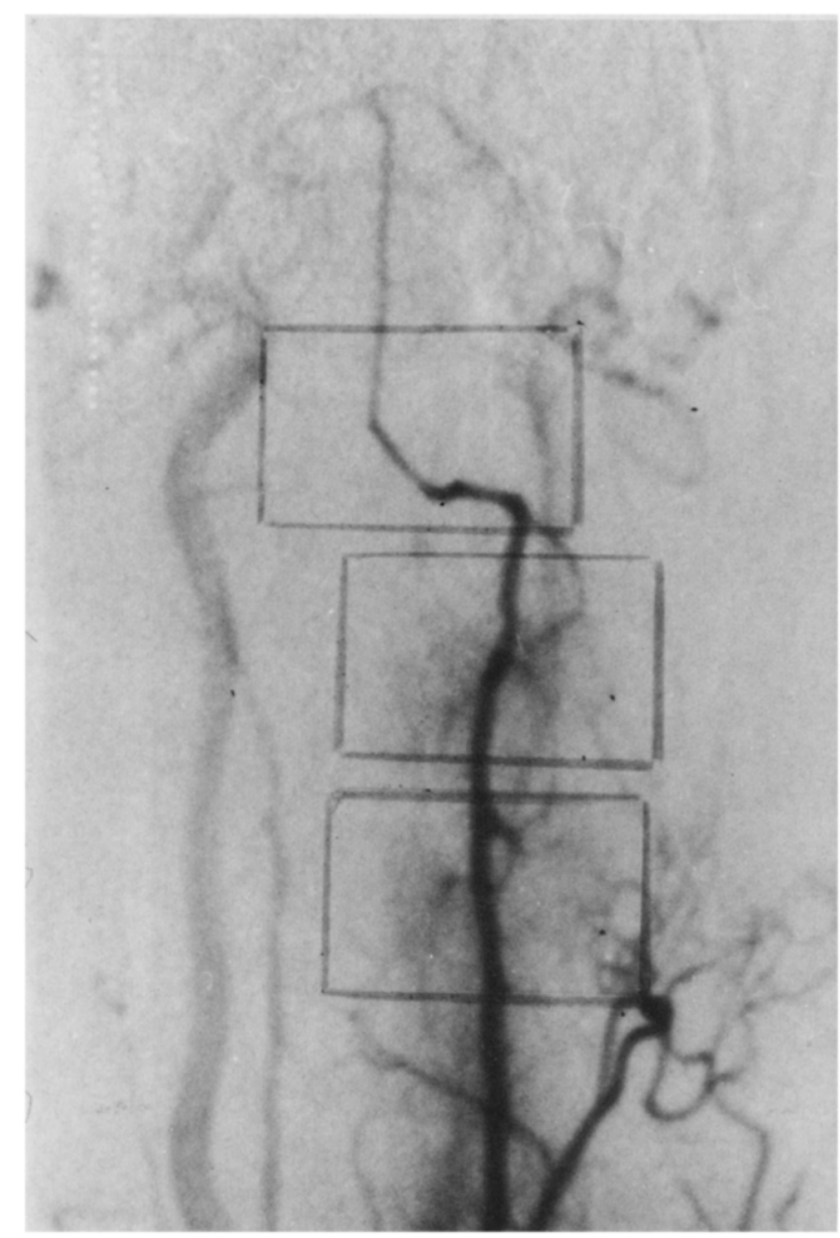

Figure 5. Angiograpby in a saline-injected animal. tic factor and a major cause of death in patients with ruptured intracranial aneurysms $[2,12]$. The pathogenesis of cerebral arterial spasm has still to be clarified in most of its aspects and the treatment results are generally unrewarding $[1,11,16,23,27,29]$.

Carefully designed experimental studies, as well as animal models reproducing the pathological events leading to the development of cerebral arterial spasm in humans, would be a useful research model. Information from this model could be used for better clarification of the pathophysiology of this pathological condition and, it is hoped, improvement in the clinical outcome. Several experimental models of SAH have been reported in the literature, with the aim of studying the development of vasospasm $[3,4,9,10,22,27,28]$.

The rabbit is a relatively inexpensive, easily available experimental animal; however, it has been used infrequently in experimental studies of SAH $[5,8,13,15,20]$. Its size allows angiography of the cerebral vessels to be performed adequately without too much sophistication needed in the technique.

Because of its proximity in philogeny to primates [21], rabbits possess comparable cerebrovascular morphological features that might also be involved in the pathogenesis of ischemic complications of $\mathrm{SAH}[6,7$, $17,25]$.

The double-injection model of SAH, recently described by Varsos et al [27] in dogs, appears to reproduce with good approximation the occurrence of delayed cerebral vasoconstriction following $\mathrm{SAH}$. Owing to the different size of the animals, an open surgical

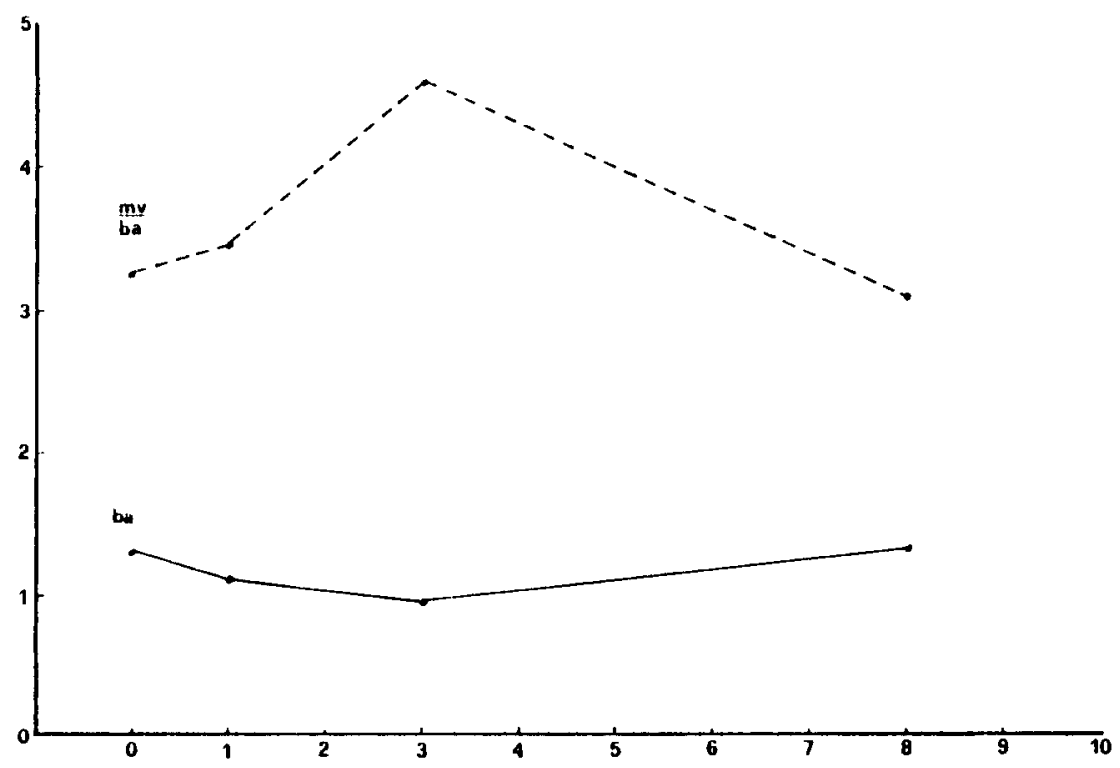

Figure 6. Graphic representation of the mean angiographic values. Top: ratio $M V / B A$ (see text). Bottom: diameters of the basilar arteries. 


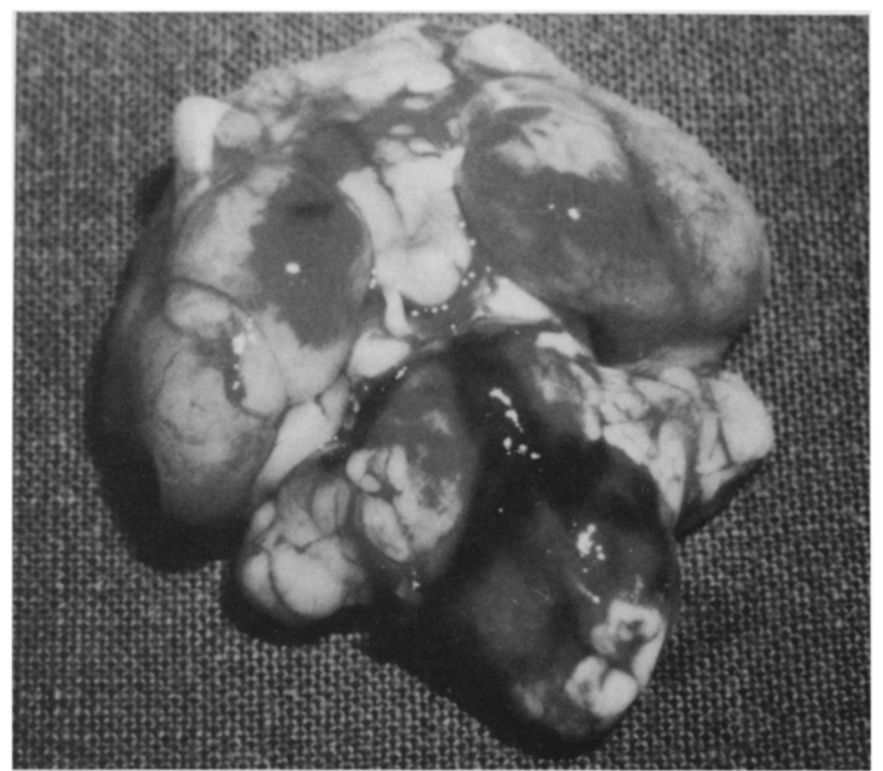

Figure 7. Pathological specimen of a day 1 group animal. A diffuse SAH is evident, mainly at the level of the prepontine cistern and around the basilar artery.

Figure 8. Computed tomography scan of a day 1 group animal; there is evidence of blood surrounding the basilar artery.

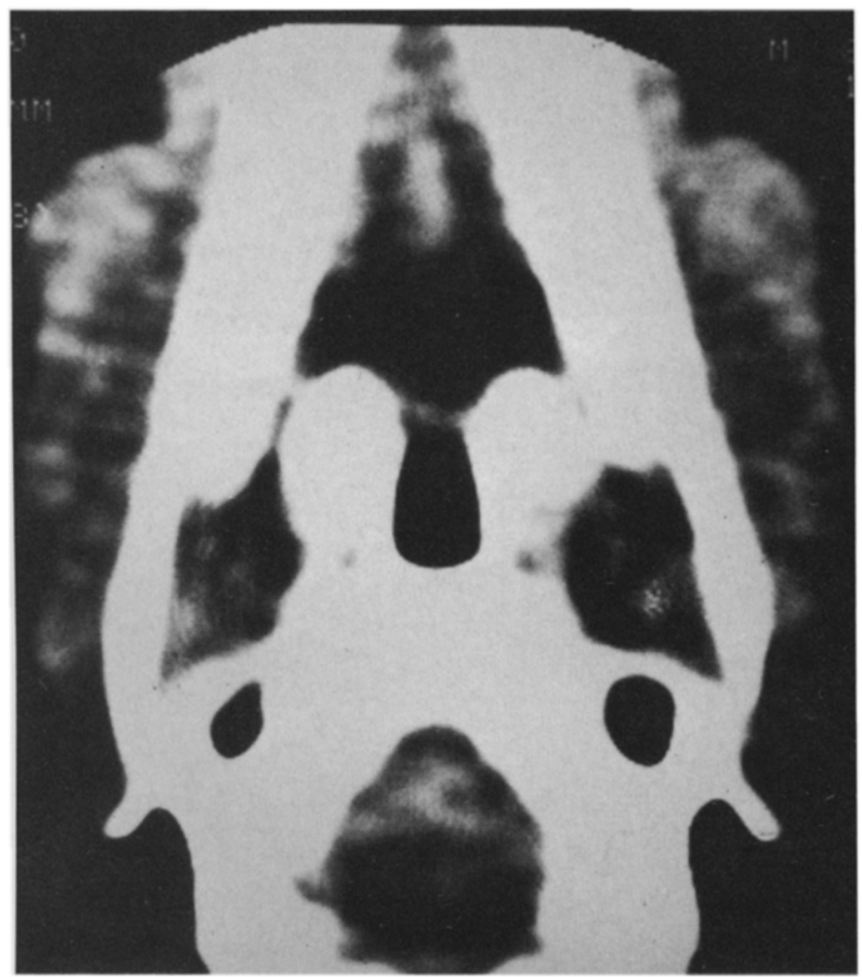

Table 1. Measurement Values in Individual Animals

\begin{tabular}{|c|c|c|}
\hline Group & $\mathrm{BA}(\mathbf{m m})$ & Ratio MV/BA \\
\hline C & 1.3 & 2.85 \\
\hline C & 1.3 & 3.85 \\
\hline C & 1.4 & 3.57 \\
\hline C & 1.5 & 3.47 \\
\hline C & 1.4 & 2.93 \\
\hline C & 1.3 & 3.46 \\
\hline C & 1 & 3.20 \\
\hline C & 1.3 & 3.31 \\
\hline C & 1.4 & 2.93 \\
\hline $\mathrm{C}$ & 1.2 & 2.78 \\
\hline D. 1 & 1 & 3.60 \\
\hline D. 1 & 1.2 & 3.68 \\
\hline D. 1 & 1.3 & 3.47 \\
\hline D. 1 & 1.0 & 3.51 \\
\hline D. 1 & 0.9 & 3.56 \\
\hline D. 1 & 0.9 & 3.88 \\
\hline D. 1 & 1.2 & 3.04 \\
\hline D. 1 & 1.1 & 3.37 \\
\hline D. 1 & 1.3 & 3.25 \\
\hline D. 3 & 1 & 4.32 \\
\hline D. 3 & 1.1 & 3.98 \\
\hline D. 3 & 0.9 & 4.67 \\
\hline D. 3 & 0.8 & 5.25 \\
\hline D. 3 & 0.8 & 5.02 \\
\hline D. 3 & 0.7 & 5.17 \\
\hline D. 3 & 0.8 & 4.52 \\
\hline D. 3 & 1.1 & 3.65 \\
\hline D.8 & 1.3 & 2.90 \\
\hline D. 8 & 1.5 & 2.98 \\
\hline D. 8 & 1.1 & 3.05 \\
\hline D. 8 & 1.2 & 2.82 \\
\hline D. 8 & 1.4 & 2.87 \\
\hline D. 8 & 1.3 & 3.32 \\
\hline D. 8 & 1.3 & 3.34 \\
\hline D. 8 & 1.3 & 3.52 \\
\hline$S$ & 1.5 & 2.63 \\
\hline$S$ & 1.25 & 3.24 \\
\hline$S$ & 1.30 & 3.15 \\
\hline
\end{tabular}

See text for statistical analysis.

Abbreviations: BA = basilar artery diameter; ratio MV/BA (see text for explanation); $C=$ control group; D. $1=$ day 1 group; $D .3=$ day 3 group; $D .8=$ day 8 group; $S=$ saline-injected animals.

technique was used in the present study to avoid accidental contamination of cerebrospinal fluid (CSF) and to obtain visual control of injection. We are not aware of other studies using a double-injection model of $\mathrm{SAH}$ in rabbits. Conflicting results regarding the occurrence of vasospasm and related changes have been reported by other studies using either a single-injection SAH model [5] or a triple-injection SAH model [13] in rabbits. The present closed skull model does not require manipulations of brain structures and allows an experimental reproduction of the effects of sudden 


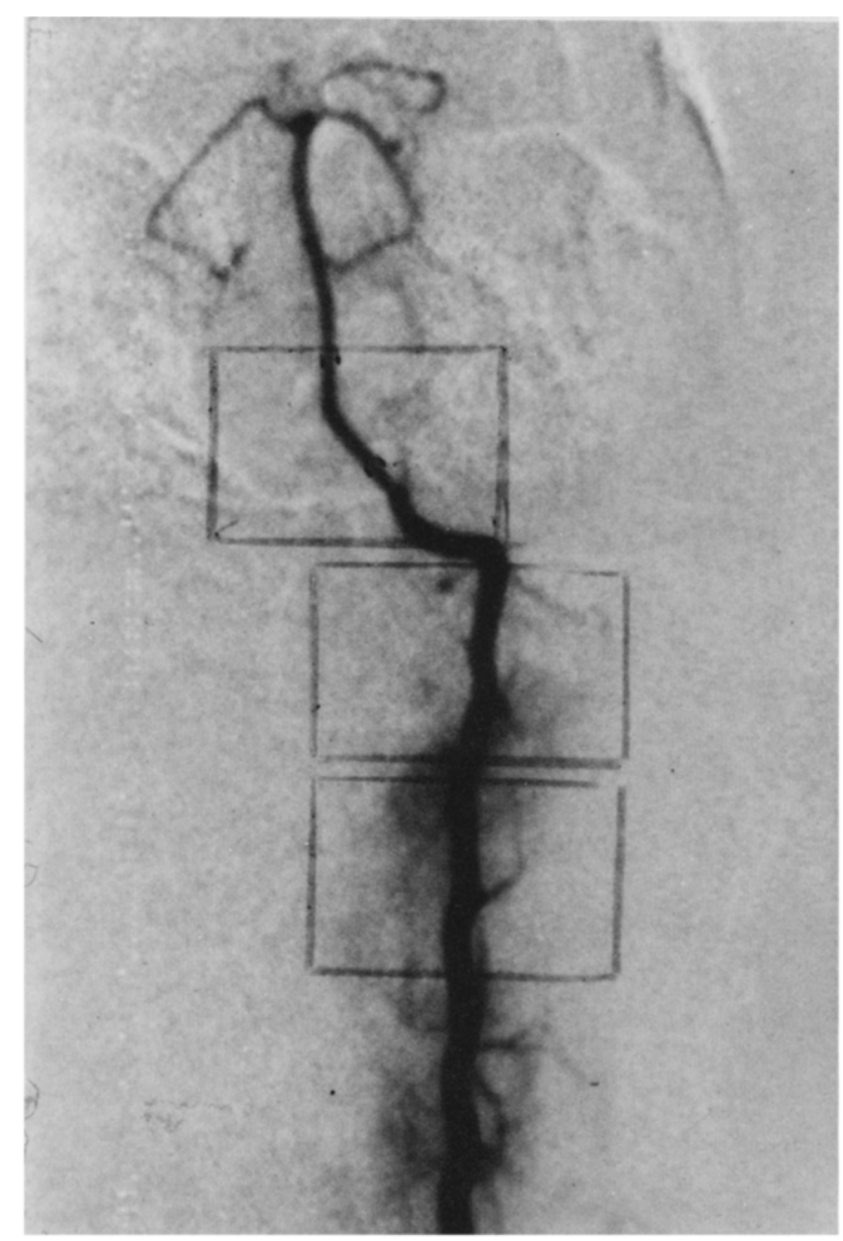

Figure 9. Group B. Angiography of number two animal before the $S A H$.

increased intracranial pressure (ICP) that occurs in human SAH. Injection of $1 \mathrm{~mL}$ of blood over 20 seconds was well tolerated by the animals. Computed tomography scanning examinations and autopsy showed clots located anteriorly around the basilar artery 1 day after the last hemorrhage, thus supporting the effectiveness of the described procedure.

Furthermore, the chosen 24-hour interval between hemorrhages allowed the animals to recover from the effect of both anesthesia and the experimental procedure. However, mortality was by no means negligible. Several factors might play a role regarding mortality. Excluding technical errors, these factors included respiratory distress, general stress owing to surgical manipulations, and sudden increased ICP. Perhaps the effects owing to raised ICP in this experimental model might be minimized by removing an equal amount of cerebrospinal fluid prior to blood injection. No particular problems were encountered when performing angi- ography in rabbits. Accurate measurements of angiographic data were essential for the purpose of the present study. Digital subtraction angiography demonstrated satisfactory angiographic images and allowed us to keep constant the possible parameters that might influence the comparison of films obtained from different animals. The possible influence of even small variations in the distance between the $\mathrm{x}$-ray source and the animal was overcome by using the ratio $\mathrm{MV} / \mathrm{BA}$ in the measurements.

In a large number of animals in which a single angiogram was performed, we observed a considerable interanimal variation in the size of the basilar artery. However, the diameter of the basilar artery appeared to be reduced in SAH animals, with a definite peak at about the third day after the last SAH. This applies well to the hypothetical timing of release of spasmogenic substances from clots accumulated in the subarachnoid spaces and their possible mechanism of action $[5,9,11$,

Figure 10. Group B. Angiography of number two animal 3 days after the second SAH.

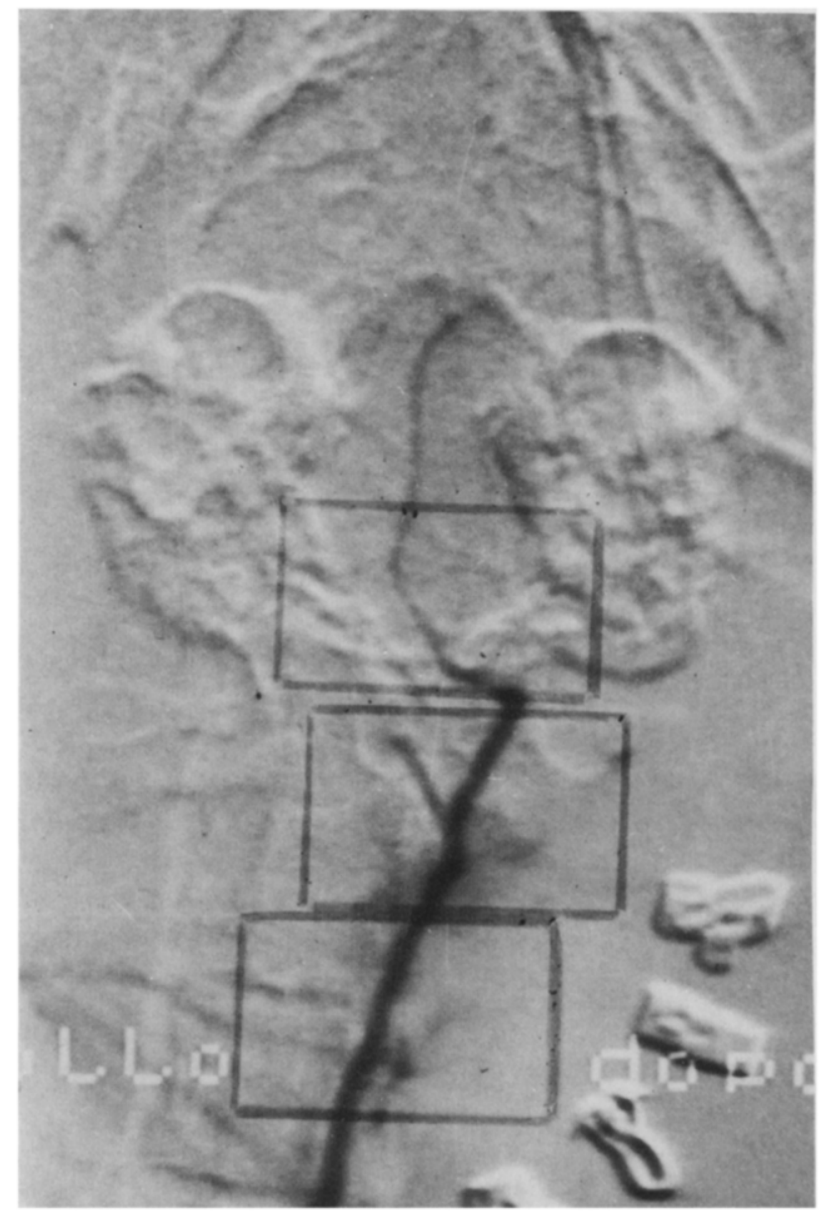




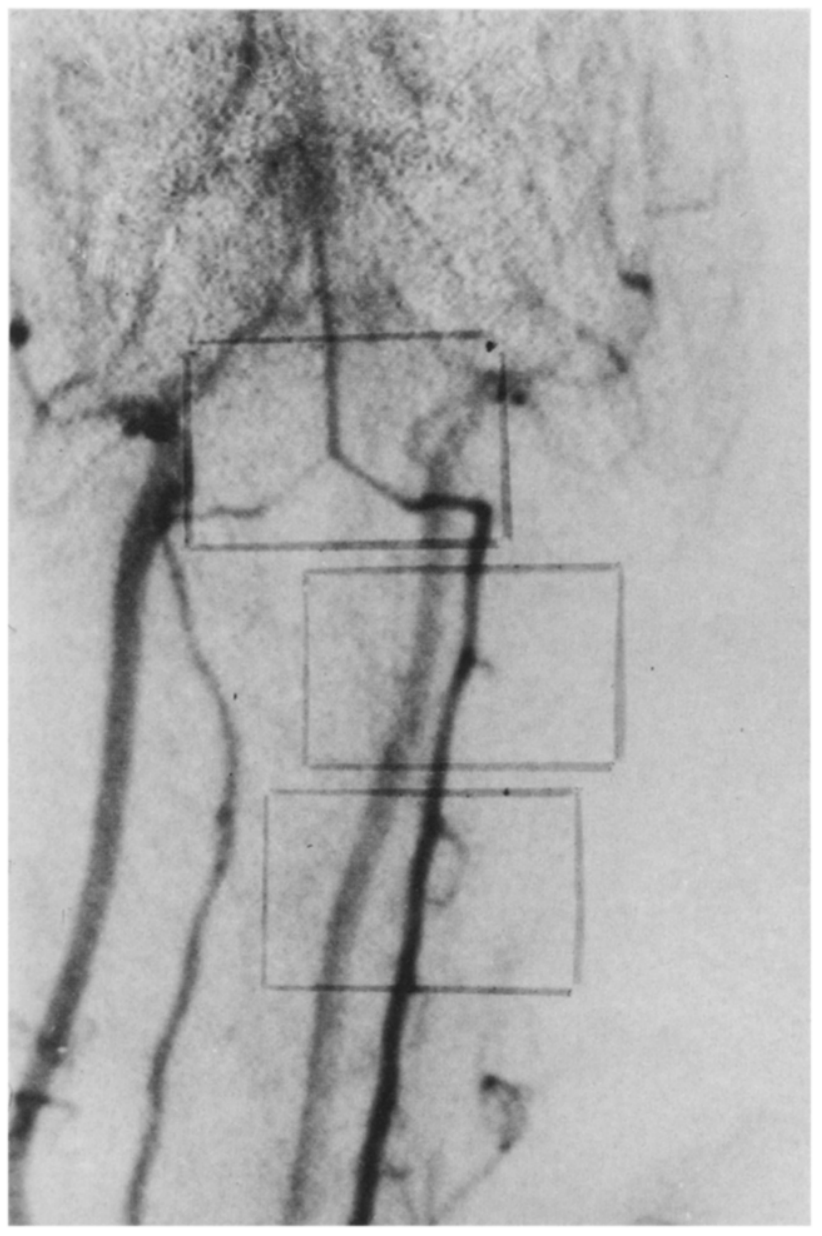

Figure 11. Group B. Angiography of number seven animal before the SAH.

$13,14,16,19,20,24,26]$. Moreover, the reduction in the diameter of "spastic" basilar artery was statistically significant.

Repeated serial angiographic studies, in the same animal, are the optimal way to assess angiographic vasospasm, particularly in models that are being pharmacologically manipulated for better clinical results. In this study, we performed repeated angiographic examinations 3 days after the second hemorrhage in the last 19 animals, in which a control angiogram had been performed prior to the experimental SAHs. Although the occurrence of a significant vasospasm of the basilar artery was demonstrated, an unacceptably high mortality rate was also recorded. We believe that multiple surgical procedures and anesthesia were mainly responsible for the disappointing death rate in the group $B$ animals. Using a longer interval between control angiogram and experimental SAH could be a possible way to reduce the mortality in this model.
The present results raise the question as to whether the validity of this model regarding the production of vasospasm is, in fact, affected by the high surgical mortality rate. In addition, there are recent suggestions $[13,18,27]$ that the double intracisternal injection of blood does not appear to enhance cerebral vasospasm (N.F. Kassel, personal communication, 1987). These studies, as well as our results, suggest a consistent limitation to the use of the present SAH model. Future studies using a single-injection model are being contemplated.

The authors are deeply indebted to the management and technical staff of "Clinica Nuova Latina," Rome, Italy, for their valued support and assistance in the angiographic studies. The authors would also like to express their thanks to James T. Goodrich, M.D., Ph.D., Department of Neurological Surgery, Albert Einstein College of Medicine, New York, for his editorial comments during the preparation of this manuscript.

Figure 12. Group B. Angiograpby of number seven animal 3 days after the second $S A H$.

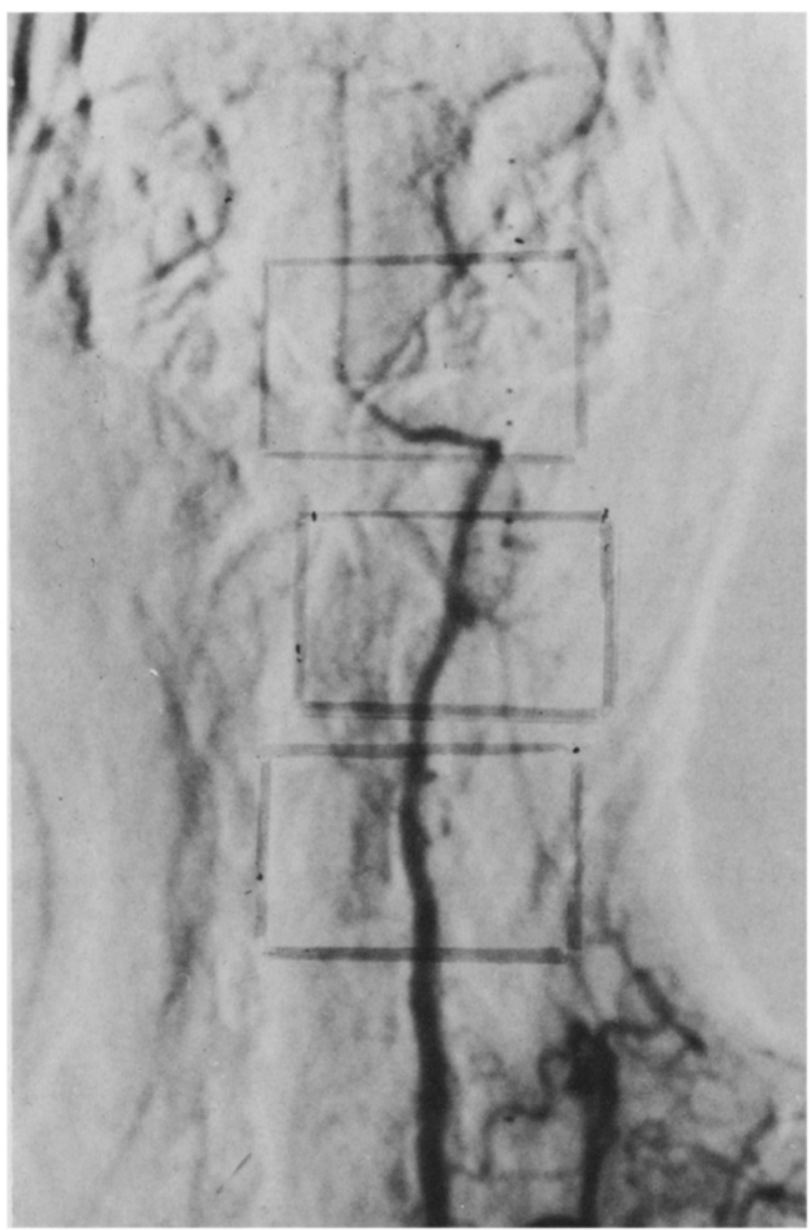


Table 2. Group B-Measurement Values in Individual Animals

\begin{tabular}{|c|c|c|c|}
\hline & & Control & Three days \\
\hline \multirow[t]{2}{*}{1.} & $\mathrm{BA}(\mathrm{mm})$ ratio $\mathrm{MV} / \mathrm{BA}$ & 1.3 & 0.9 \\
\hline & & 3.41 & 4.94 \\
\hline \multirow[t]{2}{*}{2.} & $\mathrm{BA}(\mathrm{mm})$ ratio $\mathrm{MV} / \mathrm{BA}$ & 1.3 & 0.8 \\
\hline & & 3.77 & 4.57 \\
\hline \multirow[t]{2}{*}{3.} & $\mathrm{BA}(\mathrm{mm})$ ratio $\mathrm{MV} / \mathrm{BA}$ & 1.3 & 0.9 \\
\hline & & 3.85 & 4.48 \\
\hline \multirow[t]{2}{*}{4.} & $\mathrm{BA}(\mathrm{mm})$ ratio $\mathrm{MV} / \mathrm{BA}$ & 1.4 & 0.9 \\
\hline & & 3.08 & 4.85 \\
\hline \multirow[t]{2}{*}{5.} & $\mathrm{BA}(\mathrm{mm})$ ratio $\mathrm{MV} / \mathrm{BA}$ & 1.3 & 0.8 \\
\hline & & 3.34 & 4.86 \\
\hline \multirow[t]{2}{*}{6.} & $\mathrm{BA}(\mathrm{mm})$ ratio $\mathrm{MV} / \mathrm{BA}$ & 1.4 & 1.0 \\
\hline & & 3.35 & 4.38 \\
\hline \multirow[t]{2}{*}{7.} & $\mathrm{BA}(\mathrm{mm})$ ratio $\mathrm{MV} / \mathrm{BA}$ & 1.5 & 1.0 \\
\hline & & 3.38 & 4.72 \\
\hline \multirow[t]{2}{*}{8.} & $\mathrm{BA}(\mathrm{mm})$ ratio $\mathrm{MV} / \mathrm{BA}$ & 1.4 & 1.1 \\
\hline & & 3.80 & 4.50 \\
\hline \multirow[t]{2}{*}{9.} & $\mathrm{BA}(\mathrm{mm})$ ratio $\mathrm{MV} / \mathrm{BA}$ & 1.3 & 0.9 \\
\hline & & 3.43 & 5.07 \\
\hline \multirow[t]{2}{*}{10.} & $\mathrm{BA}(\mathrm{mm})$ ratio $\mathrm{MV} / \mathrm{BA}$ & 1.3 & 1.0 \\
\hline & & 3.30 & 4.50 \\
\hline
\end{tabular}

Student's t-test: $p<0.05$.

Abbreviations: $\mathrm{BA}=$ basilar artery diameter; ratio MV/BA (see text for explanation); control $=$ control angiography values; 3 days $=$ third day angiography values.

\section{References}

1. Alksne JF, Branson PJ. Pathogenesis of cerebral vasospasm. Neurol Res 1980;2:273-82.

2. Allcock SM, Drake CG. Ruptured intracranial aneurysms: the role of arterial spasm. J Neurosurg 1965;22:21-9.

3. Allen GS, Gold LHA, Chou SN, French LA. Cerebral arterial spasm. Part 3. In vivo introcisternal production of spasm by serotonin and blood and its reversal by phenoxybenzamine. $\mathbf{J}$ Neurosurg 1974;40:451-8.

4. Barry KJ. Small animal model for investigation of $\mathrm{SAH}$ and cerebral vasospasm. Stroke 1979;10:538-41.

5. Chan RC, Durity FA, Thompson GB, Nugent RA, Kendall M. The role of the prostacyclin-thromboxane system in cerebral vasospasm following induced subarachnoid hemorrhage in the rabbit. J Neurosurg 1984;61:1120-8.

6. Conway LM, McDonald LW. Structural changes of the intradural arteries following subarachnoid hemorrhage. J Neurosurg 1972; 37:715-23.

7. Crompton MR. The pathogenesis of cerebral infarction following the rupture of cerebral berry aneurysms. Brain 1964;87: 491-510.

8. Duckles SP, Bevan R, Bevan JA. An in vitro study of prolonged vasospasm of a rabbit cerebral artery. Stroke 1976;7:174-8.

9. Echlin FA. Experimental vasospasm, acute and chronic, due to blood in the subarachnoid space. J Neurosurg 1971;35:646-56.

10. Echlin FA. Spasm of the basilar and vertebral arteries caused by experimental SAH. J Neurosurg 1965;23:1-11.

11. Kapp J, Mahaley MS, Odom GA. Cerebral arterial spasm. Part 2.
Experimental evaluation of mechanical and humoral factors in pathogenesis. J Neurosurg 1968;29:339-49.

12. Kassel NF. Timing of aneurysm surgery-Report of International Study. Presented at the 8th International Congress of Neurological Surgery, Toronto, Canada, July 1985.

13. Liszczak TM, Black PM, Tzouras A, Foley L, Zervas NT. Morphological changes of the basilar artery, ventricles, and choroid plexus after experimental SAH. J Neurosurg 1984; 61:486-93.

14. Liszczak TM, Varsos VG, Black PM, Kistler JP, Zervas NT. Cerebral arterial constriction after experimental subarachnoid hemorrhage is associated with blood components within the arterial wall. J Neurosurg 1983;58:18-26.

15. Logothetis J, Karacostas D, Karoutas G, Artemis N, Mansouri A, Milonas I. A new model of subarachnoid hemorrhage in experimental animals with the purpose to examine cerebral vasospasm. Exp Neurol 1983;81:257-78.

16. Lye RH, Paul KS, Forster CM, Whalley ET, Dutton J. Effect of fibrin-fibrinogen degradation products on human basilar artery preparations. Possible role in the etiology of cerebral arterial spasm. J Neurosurg 1982;56:339-43.

17. Mayberg MR, Houser OW, Sundt TM Jr. Ultrastructural changes in feline arterial endothelium following subarachnoid hemorrhage. J Neurosurg 1978;48:49-57.

18. Norwood CW, Poole GJ, Moody D. Treatment of experimental delayed cerebral arterial spasm with a beta ${ }_{2}$-adrenergic stimulator and a phosphodiesterase inhibitor. J Neurosurg 1976;45:491-7.

19. Ozaki N, Mullan S. Possible role of the erythrocyte in causing prolonged cerebral vasospasm. J Neurosurg 1981;55:869-76.

20. Peerless SJ, Yasargil MG. Adrenergic innervation of cerebral blood vessels in the rabbit. J Neurosurg 1979;35:773-8.

21. Petter EO, Kristiansen K, Torvik A. Subarachnoid hemorrhage and cerebrovascular spasm: morphological study of intracranial arteries based on animal experiments and human autopsies. J Neurosurg 1981;55:869-876.

22. Ritchie WL, Weir B, Overton TR. Experimental subarachnoid hemorrhage in the cynomolgus monkey: evaluation of treatment with hypertension, volume expansion, and ventilation. Neurosurgery 1980;6:57-62.

23. Sasaki T, Wakai S, Asano T, Takakura K, Sano K. Prevention of cerebral vasospasm after $\mathrm{SAH}$ with a thromboxane synthetase inhibitor, OKY-1581. J Neurosurg 1982;57:74-82.

24. Schumacher MA, Alksne JF. Mechanism of whole blood induced cerebral arterial contraction. Neurosurgery 1981;9:275-82.

25. Tanabe $Y$, Sakata K, Ito T, Takada M. Cerebral vasospasm and ultrastructural changes in cerebral arterial wall. J Neurosurg 1978;49:229-38.

26. Tanishima T. Cerebral vasospasm: contractile activity of hemoglobin in isolated canine basilar arteries. J Neurosurg 1980 $53: 312-22$

27. Varsos VG, Liszczak TM, Han DH, Kistler JP, Vielma J, Black PM, Heros RC, Zervas NT. Delayed cerebral vasospasm is not reversible by aminophylline, nifedipine, or papaverine in a "two hemorrhage" canine model. J Neurosurg 1983;58:11-7.

28. Weir B, Erasmo R, Miller J, McIntyre J, Secord D, Mielke B. Vasospasm in response to repeated subarachnoid hemorrhages in the monkey. J Neurosurg 1970;33:395-406.

29. Zabramsky J, Spetzler RF, Bonstelle C. Chronic cerebral vasospasm: effect of calcium antagonists. Neurosurgery 1986;18 $129-35$ 